\title{
Modelling Recycling Targets: Achieving a $50 \%$ Recycling Rate for Household Waste in Denmark
}

\author{
Amanda Louise Hill1 ${ }^{*}$, Ole Leinikka Dall2, Frits Møller Andersen ${ }^{3}$ \\ ${ }^{1}$ Department of Development and Planning, Aalborg University, Aalborg, Denmark \\ ${ }^{2}$ Institute of Chemical Engineering, Biotechnology and Environmental Technology, University of Southern \\ Denmark, Odense, Denmark \\ ${ }^{3}$ DTU Management Engineering, Technical University of Denmark, Roskilde, Denmark \\ Email: ${ }^{*}$ alhill@plan.aau.dk
}

Received 25 March 2014; revised 18 April 2014; accepted 15 May 2014

Copyright (C) 2014 by authors and Scientific Research Publishing Inc.

This work is licensed under the Creative Commons Attribution International License (CC BY).

http://creativecommons.org/licenses/by/4.0/

(c) (i) Open Access

\begin{abstract}
Within the European Union (EU) a paradigm shift is currently occurring in the waste sector, where EU waste directives and national waste strategies are placing emphasis on resource efficiency and recycling targets. The most recent Danish resource strategy calculates a national recycling rate of $\mathbf{2 2 \%}$ for household waste, and sets an ambitious goal of a $50 \%$ recycling rate by 2020 . This study integrates the recycling target into the FRIDA model to project how much waste and from which streams should be diverted from incineration to recycling in order to achieve the target. Furthermore, it discusses how the existing technological, organizational and legislative frameworks may affect recycling activities. The results of the analysis show that with current best practice recycling rates, the $50 \%$ recycling rate cannot be reached without recycling of household biowaste. It also shows that all Danish municipalities will need to make efforts to recover all recyclable fractions, and that the increased recycling efforts of only selected municipalities will not be sufficient to reach the target.
\end{abstract}

\section{Keywords}

Recycling Rate, Recycling Potential, Household Waste, Econometric Modeling, Waste Management

\footnotetext{
${ }^{*}$ Corresponding author.
}

How to cite this paper: Hill, A.L., Dall, O.L. and Andersen, F.M. (2014) Modelling Recycling Targets: Achieving a 50\% Recycling Rate for Household Waste in Denmark. Journal of Environmental Protection, 5, 627-636. 


\section{Introduction}

\subsection{Background}

Within the European Union (EU) a paradigm shift is currently occurring in the waste sector, where waste policies and strategies are moving away from a focus on public health, and toward an agenda of resource efficiency. This shift in paradigm is apparent in the so-called Waste Framework Directive (WFD) [1] and the EU Commission's Roadmap to a Resource Efficient Europe [2] and in the national waste strategies of the Member States; In Denmark, the newest national waste strategy has been published instead as a resources strategy [3]. The WFD sets a target of 50\% recycling of municipal solid waste to be fulfilled by 2020 .

In March of 2013, the European Environment Agency released a report detailing the recycling efforts in all the EEA countries which found that the majority of countries were not on track to reaching the target set in the WFD. The report looked at the annual rate of increase in recycling over the period 2001 to 2010, and considered if this rate of increase were continued to 2020 , would the $50 \%$ recycling target be met. 5 countries have already achieved the target, and a further 6 are on track, while Denmark is amongst the remaining 21 countries that will need to increase its efforts if it is to achieve the recycling rate [4].

Despite the fact that the EEA considered Denmark would need to increase efforts in order to achieve the target set out in the WFD, the new national resource strategy (DRS) released in October of 2013 sets an even more ambitious national target [3]. While on the surface the target appears to be the same; $50 \%$ recycling rate of household waste by 2020, a difference in the calculation method means that certain fractions of waste that are included in the recycling rate as reported to the EU are not included in the recycling rate as calculated for the DRS. Denmark reports its recycling rate to the EU based on the fourth calculation option given in connection with the WFD, where all waste that is collected under the municipal waste ordinance is considered [5]. According to this definition Denmark had a household recycling rate of $42 \%$ in 2010. The DRS defines the recycling rate to be calculated from waste that is collected from households, and specifically; biowaste, paper, cardboard, glass, plastic, wood and metal. Electronic waste, hazardous waste, and other wastes that are collected according to separate ordinances are not included, giving a recycling rate of only 22\% in 2013 [3]. The term biowaste here refers to the "wet" portion of household waste which is primarily composed of food waste, although different municipalities may have differing definitions of biowaste due to technical or hygiene considerations.

In order to increase the recycling rate, one of two actions is necessary; either the amount of non-recyclable waste needs to be decreased through prevention strategies which gives a greater proportion of waste going to recycling, or recyclable waste from the mixed waste stream needs to be diverted away from incineration and toward material recovery activities. This study assumes that all efforts to increase the recycling rate will be made through diversion of mixed household waste from incineration to recycling. Therefore this analysis of how to achieve the recycling target focuses on the composition and generation of waste in the mixed household waste stream.

While the DRS sets a very ambitious goal for municipalities to achieve, it purposefully does not address how the goal should be achieved, with the intention of allowing each individual municipality to find the solution that best fits their needs. This open approach is taken to ensure that no municipality is locked into a technological option that does not suit its needs: some municipalities are characterized as rural areas, with widely spread, single-family dwellings, while other municipalities are densely populated, inner-city areas with a high proportion of multi-family dwellings, while still others are a mixture of rural and urban. Given this diversity, it is unlikely that one technological option would be optimal for all municipalities. However, the relatively small amounts of household waste that each municipality is responsible for, render many technologies unfeasible on the municipal scale.

\subsection{State of the Art-Current Methods for Planning Recycling Systems}

Since the 1970's Denmark's waste management planning and investment in infrastructure in the waste sector has focused on the expansion of incineration and shifting waste from landfill to incineration. In the previous national waste strategy, which covered the years 2009 to 2012, the goal was to recycle at least 65\% of all waste, with no specific targets for household waste other than for the paper fraction [6]. In that strategy, the econometric model called FRIDA was used to project the amount of combustible waste that would be produced in comparison to the incineration capacity. However, this approach neglects to include the information of how much combustible 
waste will be diverted from incineration to recycling if recycling targets are to be reached. While the flow of waste from one stream to another through differences in collection will not impact the total generation of waste [7], it has the potential to affect how much waste is available for both recycling and incineration.

In order to develop an efficient strategy for achieving the recycling target, it is essential to know what the future generation of household waste will be, both in terms of amount and composition [7] [8]. To determine this information, the Danish authorities currently rely on the use of econometric models, such as the FRIDA model, which extrapolates economic and waste generation data from the past to predict the future generation of waste. However, these models do not currently take into account the political goals that are set. This investigation is an attempt to incorporate information of policies and targets with the output of the FRIDA model. For a detailed description of the model, see the article by Andersen and Larsen [9].

In a literature review of the use of mathematical models for predicting waste generation, it was found that the majority of studies in this field are carried out as part of an optimization and planning exercise [10]. This study is novel in that it applies the waste generation model for the purpose of investigating the feasibility of a political goal. Reference [11] also discusses the need to develop existing models to incorporate more aspects into an analysis.

\section{Research Approach}

\subsection{Determining the Generation and Composition of Waste Expected in 2020}

The FRIDA model was used to determine the projected generation of household waste in 2020. The model creates a projection for the future generation of waste based on historical data of how much waste has been produced and economic projections prepared by the Danish Ministry of Finance. The historical data for waste generation is sourced from the Danish Environmental Protection Agency's database which underwent major changes in the way data was collected from waste handlers in 2010. The data in the years since the change have been unreliable as the sector learns how to use the new system. Therefore, the figures used in this projection are based on the 2009 data. The data represents total household waste and includes all waste fractions that originate in households, as well as down-stream wastes such as the slag from incineration. The design of the Danish data collection system reflects the EU definition of municipal waste, which gives the national recycling rate that is reported according to the so-called Waste Framework Directive [1] [5]. Many of the fractions included in this data as household waste are not relevant according the DRS target as it relates explicitly to household waste, and not to municipal waste. Further to this, there are certain waste fractions that originate in households that are not included in the DRS definition of waste as they are legislated under different ordinances, such as in the case of batteries and WEEE. Categories of municipal and household waste that are explicitly not included in the DRS definition of household waste were not included in the projection.

Surveys to determine the composition of mixed household waste are costly and time consuming, as it requires that waste be analysed on a large scale to eliminate systematic errors such as those due to regional and seasonal differences. Perhaps for this reason, the number of studies detailing the composition of Danish household waste have been limited; only three studies have been published determining the relative amounts of different fractions of waste [12]-[14]. Two of the studies [12] [13] both interpret a single set of data, while the third study [14] builds on the data from the two previous studies and also collects a new data set. The new data collected in the 2013 study is however not representative of the entire Danish population as participating households were located in a single geographical area, and also the participating households were aware that their waste was being monitored which could compromise the validity of the results. Despite the difference in collection methods and the time difference better the samples, all three studies give a similar picture of the composition of mixed household waste. In this study, the composition of household waste is based on the data reported in [12]. It is acknowledged that the quality of this data is not desirable as the composition of the waste may have changed over this time, and further uncertainty is added considering that the composition of mixed waste is likely to continue to change in the future. In order to determine if the data was sufficiently accurate for this study, it was compared to more recent Swedish data for mixed household waste composition [15]. Sweden is geographically close and culturally similar to Denmark, and it can therefore be assumed that waste composition would be quite similar in the two countries. The comparison showed that the compositions of Danish waste from 2001 and Swedish waste from 2011 were quite similar for most waste fractions. The greatest difference was seen in the fractions of biowaste, where the ratio in Swedish data was lower than that seen in Danish household waste, and 
glass where the ration in the Swedish waste was higher than the Danish. Importantly, both sets of data show that biowaste is the dominant fraction of mixed household waste by weight. While it is acknowledged that the data relied upon for the composition of mixed household waste is, due to its age, not as accurate as desired, it is considered to be the best representation available, and of sufficient quality to determine which waste fractions should be targeted for recycling.

\subsection{Determining the Recycling Potential of Household Waste Fractions}

The information of the composition of the mixed household waste was integrated with the FRIDA projection to determine what potential each fraction of the mixed household waste has for contributing to the $50 \%$ recycling target. In order to identify how much of that potential could be recovered for recycling, in other words, how much of the potential could be utilized, the projected potentials were compared to best practice recycling rates. A recent report looked into the potential recycling rate that could be achieved in Denmark for different fractions of waste based on both Danish experiences and experiences of Sweden and Germany [14]. The report considered 2 different rates for recycling for single family households, and a lower rate for multi-family dwellings. The two different rates were applied in this study with the higher recycling rate being used as a best case scenario, and the lower rate being applied as a lower recycling rate. The assumed recycling rates can be seen in Table 1 . In the case of metals, the lower assumed recycling rate is lower than the projected recycling rate for 2020 considering no changes. In this case, the projected recycling rate was used as a lower value.

The data was then represented in 5 different scenarios. Scenario 1 represents a "best case", where all municipalities recycle all fractions optimally. Scenario 2 assumes the high recycling efficiency can be obtained for all dry recyclable fractions, but that biowaste recycling is not adopted by any municipalities not currently collecting biowaste for recycling. Scenarios 3 and 4 assume the lower rate of recycling efficiency, with all municipalities collecting biowaste in Scenario 3, while in scenario 4biowaste is not expanded past current efforts. Scenario 5 assumes that there is no change in recycling activities through to 2020 and is included as a baseline. The scenarios are designed to test the importance of biowaste recycling, as it has been recognized by other authors as being necessary to recycle in order to achieve high recycling rates [14] [15] [17].

\section{Results}

As shown in the Figure 1 and Figure 2, the baseline projection shows that the total amount of waste expected in the future will continue to increase. While both the combustible and recycling streams are expected to increase, the combustible stream is projected to experience a greater increase than the recycling stream. Consequently without taking any action either to increase recycling rates or to prevent the generation of combustible waste, the recycling rate in 2020 is lower than it is today (although it is important to note that based on 2009 figures the current recycling rate as calculated for this study is slightly higher than that published in the DRS). In the data supplied from the Danish waste database we can see that the majority of the waste in the combustible category is collected through the daily mixed waste collection. The projected increase in waste generation can be seen in Figure 1.

Table 1. Recycling rates applied to mixed household waste. Based on data from [16].

\begin{tabular}{cccc}
\hline \multirow{2}{*}{ Waste fractions } & \multicolumn{3}{c}{ Applied recycling rates } \\
\cline { 2 - 4 } & Upper recycling rate & Lower recycling rate & Recycling rate in 2009 \\
\hline Biowaste & 0.7 & 0.5 & $0.06^{\mathrm{a}}$ \\
Paper and Carsboard & 0.9 & 0.7 & 0.49 \\
Plastic & 0.6 & 0.4 & 0.09 \\
Glass & 0.85 & 0.85 & 0.58 \\
Metal & 0.8 & 0.6 & 0.76 \\
\hline
\end{tabular}

${ }^{\mathrm{a}} 2009$ recycling rate for biowaste applied in scenarios 1 and 3 . 


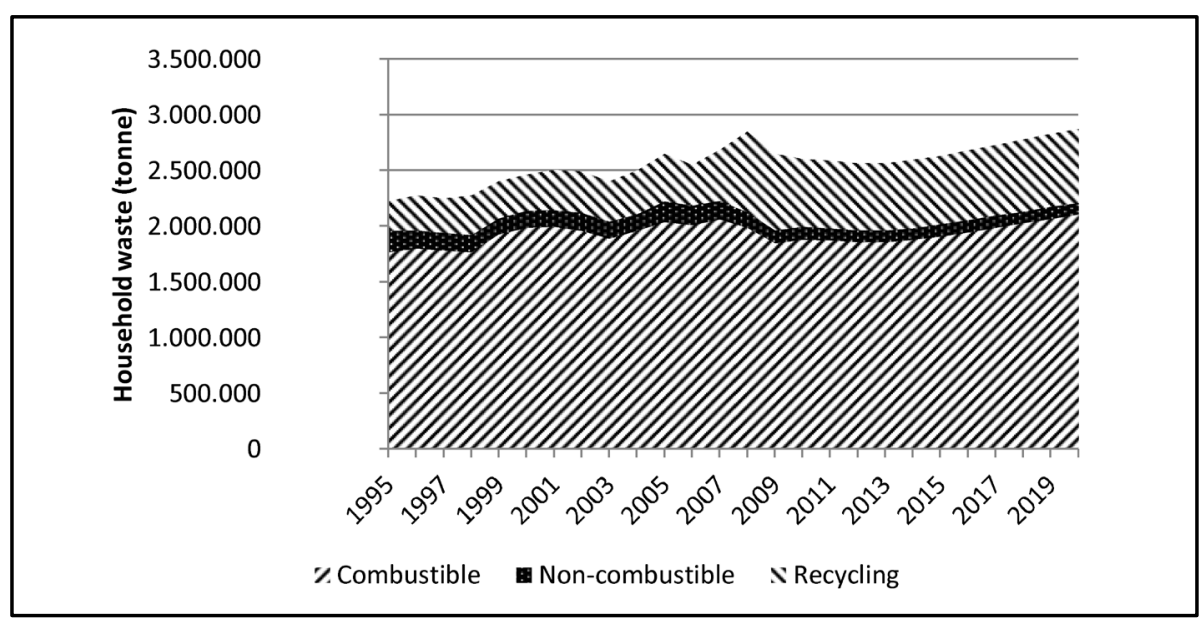

Figure 1. Baseline projection of waste generation and handling in tonne per year.

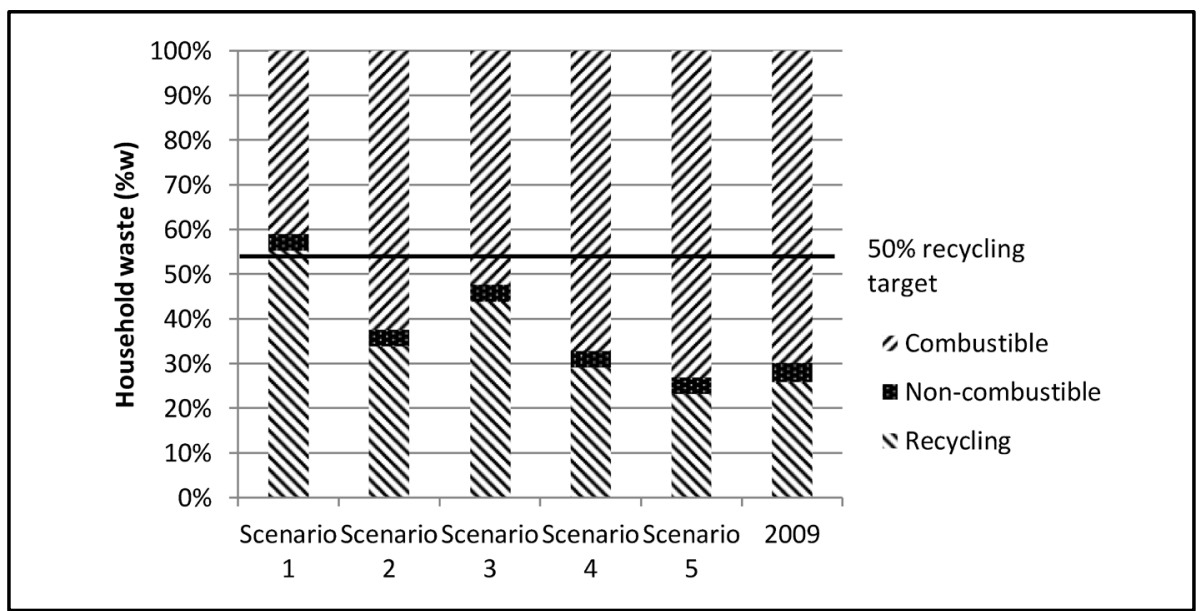

Figure 2. Handling of waste in alternative scenarios. The recycling rate reaches the $50 \%$ target only in scenario 1 which assumes a high recycling rate for all fractions.

While it was possible to project in tonnes how much waste will be diverted from incineration to recycling, it was not possible to determine exactly what effect this will have on total amounts of waste going to Danish incineration plants. This is due to the fact that generation of domestic industrial waste is not included. However, we can see that in the most optimistic scenario, the amount of waste diverted away from incineration represents $22 \%$ of the total 4.2 million tonnes of installed incineration capacity in Denmark [18].

Scenario 5, the base scenario, shows that without any efforts to increase the recycling we can only expect a recycling rate of $23 \%$. The best case scenario, scenario 1, exceeds the target with a recycling rate of 55\%. Scenarios 2, 3 and 4 all project recycling rates lower than the $50 \%$ target. The flows of waste in each of the scenarios can be seen in Figure 2. In Figure 3, the total amount of each fraction recycled in each scenario is represented.

\section{Discussion}

\subsection{Potential for Recycling}

The biowaste fraction is, by weight, the largest fraction of the mixed household waste and is also one of the least recycled fractions. Biowaste therefore represents the greatest potential for reaching the target, as can be seen in Figure 3. Only a handful of the 98 Danish municipalities currently have collection and recycling systems for household biowaste, and based on this current effort the projected recycling rate for household biowaste is only 


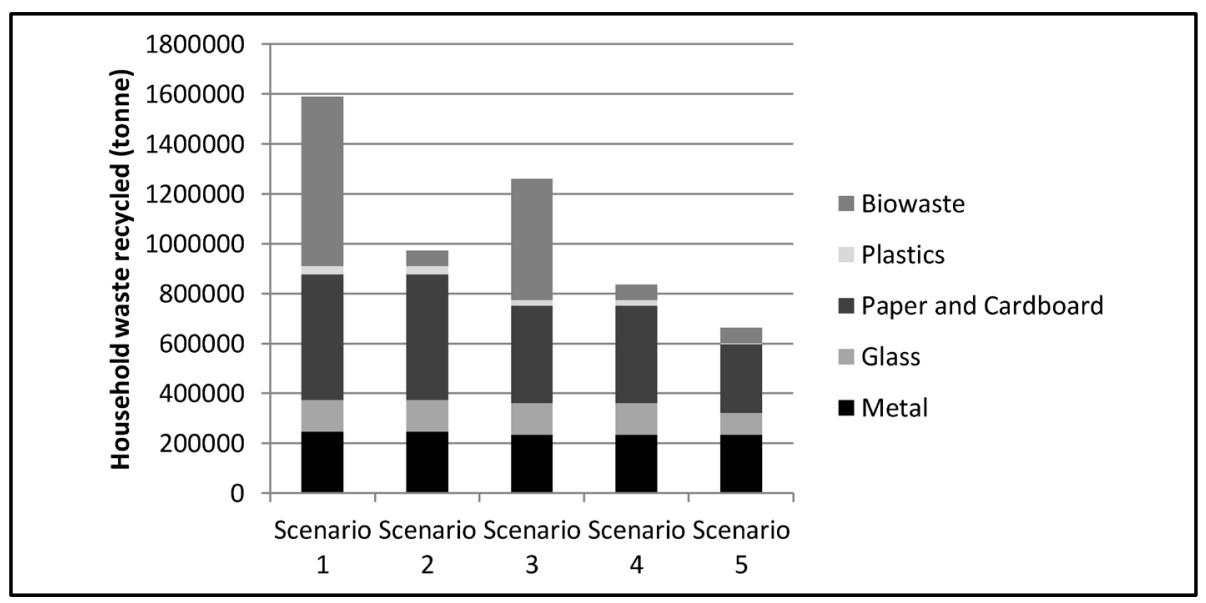

Figure 3. The amount in tonne of each fraction recycled in the different scenarios. This figure shows the amount in tonne recycled of each fraction in the different scenarios. The greatest variation and potential to contribute to the recycling rate is in the biowaste fraction.

expected to be $0.06 \%$ in 2020 , which is far short of the theoretical recycling rate that could be achieved of $50 \%$ $70 \%$.

In terms of the dry recyclables, the plastics fraction represents the largest potential, as it represents a large percentage by weight of the mixed waste. Also plastics are currently not widely collected from households for recycling, with only small amounts being collected at recycling stations through bring systems. While paper and glass are already collected either with kerbside or residential collection points in most municipalities, some potential still exists for further recycling of these fractions. Metals represent only a small fraction, and a system already exists to recycle many metals from the ashes after incineration.

The 5 scenarios show, the potential of all the dry recyclable streams is not sufficient to reach the $50 \%$ recycling target. In scenario 2, where recycling of biowaste is not expanded beyond today's efforts, the projected recycling rate is only projected to be $34 \%$. This indicates that the efforts required to reach the recycling target of $50 \%$ by 2020 will require a significant effort from all municipalities. However, this analysis assumes that all efforts to increase the recycling rate should come from the mixed household waste stream. Other waste streams may also have a good potential to contribute to the recycling rate. Two possible waste streams that could be investigated are the "bulky waste" that is collected from residential areas, and the "small and large combustible" waste stream collected at the recycling stations. The compositions of these two streams are currently unknown, and they are likely to differ between municipalities. Alternatively, a large potential may exist in increasing garden waste collection. The projection indicates that this alone could increase the Danish recycling rate to a level which would achieve the WFD target, however garden waste is not included as one of the household waste streams contributing to the DRS target.

\subsection{Technological Considerations}

While the biowaste fraction shows the greatest potential for contributing to the recycling target, it is possibly the fraction with the most technological hurdles. The biowaste fraction is also sometimes referred to as the "wet fraction" as it has a high water component and is biodegradable. These characteristics of the waste have implications for how it should be treated in respect to the other fractions. Source separation prevents contamination of organic material with potentially hazardous substances in the mixed stream, and inversely contamination of dry recyclables with organic matter. Unlike dry recyclables which are stable and can be stored for longer periods of time, biowaste should be collected regularly from residents to reduce smells and attracting pests and rodents.

A few Danish municipalities already collect biowaste for treatment at anaerobic digestion facilities [19], and some experiences also exist from biowaste collection trials in Denmark and neighbouring Sweden [12] [20] [21]. The methods of collection differ in different municipalities, and even more technological solutions exist in other EU countries. The municipality of Vejle in central Denmark has one of the most efficient systems which is based 
on optical technology, where green coloured bags containing biowaste are mechanically separated from black bags containing mixed waste.

Dry recyclables represent their own share of difficulties. Recycling collection schemes can in general be sorted into different categories: central sorting or source separation. In most instances the quality of recyclables achieved through source separation schemes is higher than that achieved through central sorting. The quality of the recyclable materials affects what purposes it can be used for and also the price for which it can be traded. However, source separation can be a politically unpopular option as it occupies more time and space for the citizen. The infrastructure requirements at the street level can also be a major cost. For example, in the Danish municipality of Aarhus, recycling bins for several different dry fractions have been installed below street level. While this is considered a low-cost option once the infrastructure has been established, the cost of expanding such a system to include all recyclable streams would likely be too costly. However, the question of central sorting versus source separation is not an either-or question, as some level of source separation is required for central sorting systems, and sorting of recyclables is also necessary in source separated waste. This is particularly important for the recycling of plastics, as different types of plastic should be separated for recycling.

In the case of metals, there is currently a high rate of recycling due to a system where they are harvested from the ashes after incineration. However, it must be considered how the calorific value of the mixed waste will be changed if biowaste and dry recyclables are removed. Socio-economic analyses would have to be conducted to determine if the increased quality of metals recovered through a collection scheme would justify the cost of separating the metals before incineration.

A third technological option, which is currently being trialed in Copenhagen, is a central sorting of mixed household waste, where both organic matter and dry recyclables are recovered for recycling. This process, called ReneScience, uses enzymes to break-down organic matter into a high energy "soup", which can be stored and used to produce biofuels. The other materials in the mixed waste stream; metals, glass, plastic, are not affected by this enzymatic process and are available for recycling after a mechanical sorting process. However, one implication of this technology for established recycling rates is that paper handled in this system is recycled together with other organic components, and is therefore not available for traditional paper recycling. Also, as the technology is still in a test phase, it is likely not feasible that it can be implemented on a nation-wide scale in the short time-span before the 2020 deadline.

In Denmark one of the major technological challenges is the low quantities of waste. Given the high costs associated with establishing a mechanical sorting plant for recyclables, it is likely that most municipalities will need to co-invest in such facilities. Another technological challenge for Denmark is the lack of domestic recycling operations which could set a specific demand for the quality of recyclables. This means that dry recyclables recovered by municipalities are largely destined to be sold on the global materials markets.

\subsection{Legislative Considerations}

The organizational structure of the waste sector is such that each municipality is responsible for the collection and treatment of all household waste produced within their boundary. Until 2010, this municipal responsibility also included industrial waste produced within the municipal boundary, but a recent liberalization of industrial waste diverts recyclable industrial waste away from municipal facilities, and potentially also combustible industrial waste. Each municipality has recycling stations where citizens can bring their pre-sorted recyclables, from where they are sold on to recycling facilities in other countries, but collection of recyclables from residential areas is in general limited to only paper and glass. This organizational structure and the technological focus on incineration has meant that recycling efforts have been decentralized and investments in advanced sorting or treatment technologies have not taken place.

The decentralized nature of waste handling in Denmark can be considered a barrier to the establishment of central sorting facilities. In order to ensure a large enough waste stream for economic viability, it would require several municipalities to collectively invest in a central sorting facility. There is a good precedent for this kind of collaboration between Danish municipalities in the field of waste management, such as in the collectively owned waste incineration facilities. The majority of Denmark's 27 dedicated waste incineration facilities are owned by a collective of municipalities [18]. This indicates that collaboration between municipalities for the purpose of economically efficient waste management is an institutionalized aspect of the DK waste sector. Therefore it would be reasonable to assume that Danish municipalities could collaborate for the purpose of investing in central 
sorting facilities. However, it is worthy to note that the federal government supported and encouraged the building of incineration facilities, through the establishment of economic tools, and requiring municipalities to ensure that there is available incineration capacity to treat waste that cannot be recycled. If we are to see a similar scale of investment in central sorting facilities as was seen for incineration facilities in the 70's and 80's, it may be necessary for the Danish government to support the investment with similar legislative tools.

The goal of 50\% recycling of household waste by 2020 is not the only ambitious goal Denmark has set itself on environmental grounds. Some of these environmental goals have the potential to form a synergy with the recycling target. While anaerobic digestion of household organic waste has previously shown to give no socio-economic benefit in Denmark [12], targets to utilize at least 50\% of animal slurry for energy production to be fossil-fuel free mean that there is potential to create a market where organic waste is in demand. In order to make the anaerobic digestion of animal slurry economically viable, AD facilities demand a high quality waste stream, such as household organic waste for co-digestion [22] [23]. Therefore, if both these targets are to be met, there is likely to be an increasing demand for source-separated household organic waste. While some technologies exist to separate organic waste from mixed waste, such as the ReneScience technology, the resulting organic waste fraction is not as of high a quality than that seen in source-separated waste, as it tends to have more contaminants such as small pieces of plastic [24]. These contaminants remain in the sludge after the digestion process, and their presence can affect the usability of the sludge for purposes such as spreading on farmland.

While Danish regulation currently allows for the use of organic household waste as a soil amendment, there exist tight restrictions for its use, the legislation currently only includes the use of organic household waste that is source-separated [25]. It is expected that the regulation of waste for agricultural purposes is likely to become more restrictive in the future, rather than more encompassing.

\subsection{Integrating Political Goals into the FRIDA Model}

Through integrating the recycling target into the FRIDA projection, we get both a better idea of what fractions should be recycled in order to achieve the target, as well as being able to determine how much waste will be left over for recycling. If information such as this is integrated into econometric projections performed at the level of individual incineration plants, it would be possible for plant owners to have a better idea of how waste flows for incineration will change in relation to the installed incineration capacity. As it is economically desirable to operate an incineration plant at full capacity, many incineration plants will choose to import industrial waste from abroad or invest in biomass resources. Since 2008, quantities of waste going to incineration have been falling in Denmark. Currently, many incineration plants have been utilizing stored waste to make up the difference. However this is a limited supply and with the large amounts of waste that will be diverted due to increased recycling, new sources of waste will have to be found. Some Danish incineration plants are already importing waste, with imports representing up to $40 \%$ of waste at some plants. Being able to project how quantities of combustible household waste are likely to fall due to increased recycling can help plant owners to create long-term plans for importing of waste.

\section{Conclusions and Future Perspectives}

The investigation into the composition of the mixed household waste reveals that the potential for the dry recyclable fractions to contribute to the recycling rate of household waste is not sufficient to reach the goal. Only in a scenario where all recyclable fractions, including organic waste, are recycled at an optimal rate will these efforts lead to a recycling rate over $50 \%$ for all household waste. Neither organic waste recycling nor dry materials recycling alone has the potential to reach the household recycling rate of $50 \%$ and a coordinated effort incorporating all recyclable streams will be necessary. Furthermore, it will be necessary for all Danish municipalities to recycle all fractions: The target will not be reached if each municipality only targets 1 or 2 fractions for increased recycling. As the investigation shows that significant efforts will need to be made by all municipalities in order to achieve the goal, it is recommended that other household waste streams be further investigated to determine what potential lies there. For example, mixed streams such as those collected as "bulky waste" or as "small and large combustible" at recycling stations could similarly be diverted to the recycling stream. The first step would be to establish what the composition of these waste fractions is.

The analysis shows that if the recycling target is reached, the amount of waste diverted from incineration represents around $20 \%$ of the current installed incineration capacity. While it is not possible to draw any detailed 
conclusions about the effect of this, without investigating the individual waste flows and economies of individual incineration plants, it can be concluded that in 2020 there will either be closures of less-economical waste incineration plants, or an increased import of combustible industrial waste.

While it has been possible to integrate the political goal into the FRIDA projection, thereby modelling the effect of increased recycling on the future waste streams, this modelling that has been undertaken in this study is somewhat underdeveloped, and is not capable of feeding information back into the FRIDA model. If political goals such as recycling targets could be integrated into projection models such as FRIDA, then the models could also give a much more detailed view at the strategic level of what goals are realistic to set, and could ensure that the government strategy is in harmony with the organizational and technological structure of the waste sector.

\section{Acknowledgements}

This work was supported by the Danish Strategic Research Council as part of the TOPWASTE project.

\section{References}

[1] European Parliament and Council (2008) Waste Framework Directive.

[2] European Commission (2011) Roadmap to a Resource Efficient Europe. OPOCE, Brussels.

[3] Danish Ministry of the Environment (2013) Danmarkudenaffald: Genanvend mere-Forbrændmindre. Copenhagen.

[4] Fischer, C., Gentil, E., Ryberg, M. and Reichel, A. (2013) Managing Municipal Solid Waste-A Review of Achievements in 32 European Countries-European Environment Agency (EEA). Luxembourg.

[5] European Commission (2011) 2011/753/EU: Commission Decision of 18 November 2011 Establishing Rules and Calculation Methods for Verifying Compliance with the Targets Set in Article 11(2) of Directive 2008/98/EC. http://eur-lex.europa.eu/legal-content/EN/TXT/?uri=CELEX:32011D0753

[6] Danish Ministry of the Environment (2009) Regeringens Affaldsstrategi 2009-12 1. Delstrategi. Copenhagen.

[7] Beigl, P., Lebersorger, S. and Salhofer, S. (2008) Modelling Municipal Solid Waste Generation: A Review. Waste Management, 28, 200-214. http://dx.doi.org/10.1016/j.wasman.2006.12.011

[8] Chen, H.W. and Chang, N.-B. (2000) Prediction Analysis of Solid Waste Generation Based on Grey Fuzzy Dynamic Modeling. Resources, Conservation and Recycling, 29, 1-18. http://dx.doi.org/10.1016/S0921-3449(99)00052-X

[9] Andersen, F.M. and Larsen, H.V. (2012) FRIDA: A Model for the Generation and Handling of Solid Waste in Denmark. Resources, Conservation and Recycling, 65, 47-56. http://dx.doi.org/10.1016/j.resconrec.2012.04.004

[10] Abou Najm, M., El-Fadel, M., Ayoub, G., El-Taha, M. and Al-Awar, F. (2002) An Optimisation Model for Regional Integrated Solid Waste Management I. Model Formulation. Waste Management \& Research, 20, 37-45. http://dx.doi.org/10.1177/0734242X0202000105

[11] Pires, A., Martinho, G. and Chang, N.-B. (2011) Solid Waste Management in European Countries: A Review of Systems Analysis Techniques. Journal of Environmental Management, 92, 1033-1350. http://dx.doi.org/10.1016/j.jenvman.2010.11.024

[12] Petersen, C. and Domela, I. (2003) Sammensætningafdagrenovationogordninger for hjemmekompostering (Composition of Household Waste and Schemes for Home Composting, in Danish). Danish Ministry of the Environment, Copenhagen.

[13] Riber, C., Petersen, C. and Christensen, T.H. (2009) Chemical Composition of Material Fractions in Danish Household Waste. Waste Management, 29, 1251-1257. http://dx.doi.org/10.1016/j.wasman.2008.09.013

[14] Møller, J. and Jensen, M.B. (2013) Miljø-ogsamfundsøkonomiskvurderingafmuligheder for øgetgenanvendelseafpapir,pap, plast, metal ogorganiskaffald fradagrenovation (Environmental and Socio-Economic Analysis of Possibilities for Increased Recycling of Paper, Cardboard, Metal and Organic Waste). Danish Ministry of the Environment, Copenhagen.

[15] Bernstad, A., La Cour Jansen, J. and Aspegren, H. (2012) Local Strategies for Efficient Management of Solid Household Waste-The Full-Scale Augustenborg Experiment. Waste Management \& Research, 30, 200-212. http://dx.doi.org/10.1177/0734242X11410113

[16] Bagge, L., Münter, C.F., Justesen, J.S., Carlsbæk, M., Heidemann, R. and Møller, M.S. (2010) Idékatalogtiløgetgenanvendelseafdagrenovation-Sortering i to ellerflerefraktioner (Idea Catalogue for Increased Recycling of Municipal Waste, in Danish). Danish Ministry of the Environment, Copenhagen.

[17] La Cour Jansen, J., Spliid, H., Hansen, T.L., Svärd, A. and Christensen, T.H. (2004) Assessment of Sampling and Chemical Analysis of Source-Separated Organic Household Waste. Waste Management, 24, 541-549. 
http://dx.doi.org/10.1016/j.wasman.2004.02.013

[18] Affaldsforening, D., Industri, D. and Energi, D. (2012) BEATE Benchmarking afaffaldssektoren 2012 (BEATE Benchmarking of the Waste Sector 2012, in Danish). http://mst.dk/media/mst/Attachments/Forbrndingbenchmarkingfor2011.pdf

[19] Hansen, E. (1992) Vejlesaffaldssystem, Miljøprojekt nr. 208 (The Waste System of Vejle, in Danish). Danish Ministry of the Environment, Copenhagen.

[20] Bernstad, A. and La Cour Jansen, J. (2012) Separate Collection of Household Food Waste for Anaerobic DegradationComparison of Different Techniques from a Systems Perspective. Waste Management, 32, 806-815. http://dx.doi.org/10.1016/j.wasman.2012.01.008

[21] Hansen, T.L., La Cour Jansen, J., Davidsson, A. and Christensen, T.H. (2007) Effects of Pre-Treatment Technologies on Quantity and Quality of Source-Sorted Municipal Organic Waste for Biogas Recovery. Waste Management, 27, 398-405. http://dx.doi.org/10.1016/j.wasman.2006.02.014

[22] Lindboe, H.H. and Energistyrelsen, D. (1995) Progress Report on the Economy of Centralized Biogas Plants. Danish Energy Agency, Copenhagen.

[23] Nielsen, L.H., Hjort-Gregersen, K., Thygesen, P. and Christensen, J. (2002) Samfundsøkonomiskeanalyserafbiogasfællesanlæg (Socio-Economic Analysis of Centralised Biogas Plants, in Danish). Fødevareøkonomisk Institut, Frederiksberg, Denmark.

[24] Braber, K. (1995) Anaerobic Digestion of Municipal Solid Waste: A Modern Waste Disposal Option on the Verge of Breakthrough. Biomass and Bioenergy, 9, 365-376.

[25] Danish EPA (2010) Anvendelseafaffaldtiljordbrugsformål (Application of Waste for Agricultural Purposes, in Danish). Copenhagen. 